\title{
Correction to: Pegylated interferon beta-1a (Plegridy) Italian real-world experience: a Delphi analysis of injection-site reaction and flu-like symptom management
}

\author{
Cinzia Cordioli $^{1} \cdot$ Graziella Callari $^{2} \cdot$ Roberta Fantozzi $^{3} \cdot$ Francesca Caruso $^{2} \cdot$ Giuseppe Martucci $^{3} \cdot$ Santa Mascara $^{1}$. \\ Valentina Zipoli ${ }^{4}$
}

Published online: 22 January 2021

(C) Fondazione Società Italiana di Neurologia 2021

Correction to: Neurological Sciences (2021). https://doi.org/10.1007/s10072-020-04969-3

The original article contains an error. In Table 1, the statement 11 bis has been deleted. The correct Table 1 is presented here. The original article has been corrected.

The online version of the original article can be found at https://oi.org/ 10.1007/s10072-020-04969-3

Cinzia Cordioli

cinzia.cordioli@gmail.com

Spedali Civili di Brescia, Multiple Sclerosis Centre, Brescia, Italy

2 Fondazione Istituto G.Giglio, Cefalù, Italy

3 IRCCS Neuromed, Pozzilli, Italy

4 Biogen, Cambridge, MA, USA
Table 1 Delphi questionnaire

Questions

1. During the first 6 months of treatment, in most cases, FLS occurs from 6 to $12 \mathrm{~h}$ after the injection

2. During the first 6 months of treatment, in most cases, FLS lasts up to $48 \mathrm{~h}$

3. During the first 6 months of treatment, in most cases, fever lasts up to $12-24 \mathrm{~h}$

4. In my clinical experience, FLS is the main reason of drop-out

5. During the first 6 months of treatment, in most cases, the intensity of FLS is mild ( mild $=$ fever $<37.5^{\circ}$ )

6. During the first 6 months of treatment, FLS significantly impacts patients' quality of life

7. During the first 6 months of treatment, in most cases, the intensity of the FLS improves

8. In most patients ISR resolves over a week

9. ISR does not improve over time (ie ISR occurs at each injection and its intensity does not reduce)

10. In most cases the ISR is erythematous

11. ISR does not significantly impact on the patient's quality of life

$11 \mathrm{bis}$. ISR impact of injective therapies on the patient's quality of life is related to the frequency of administration

12. Aesthetic issues are mainly responsible of drop-outs due to ISR

13. The characteristics of the ISR depend on injection site

14. In my clinical experience, the ISR development is the main factor of drop out

15. Adequate information on the tolerability profile improves adherence to treatment

16. Adequate patient empowerment on therapy management improves adherence to treatment

17. In my clinical experience, paracetamol is the drug of first choice for FLS treatment

18. The characteristics of FLS and ISR vary from individual to individual. It is advisable for the patient to learn to manage them independently depending on how they occur

19. It is important to provide specific information also to the patient switching from other IFNs to peginterferon beta-1a

Publisher's note Springer Nature remains neutral with regard to jurisdictional claims in published maps and institutional affiliations. 